See next page 


\title{
Improved Aerosol Optical Depth and Ångstrom Exponent Retrieval Over Land From MODIS Based on the Non-Lambertian Forward Model
}

\author{
Leiku Yang, Yong Xue, Senior Member, IEEE, Jie Guang, Hassan Kazemian, Senior Member, IEEE, \\ Jiahua Zhang, and Chi Li
}

\begin{abstract}
In this letter, an improved algorithm for aerosol retrieval is presented by employing the non-Lambertian forward model (forward model) (NL_FM) in the Moderate Resolution Imaging Spectroradiometer (MODIS) dark target (DT) algorithm to reduce the uncertainties induced when using the Lambertian FM (L_FM). This new algorithm was applied to MODIS measurements of the whole year of 2008 over Eastern China. By comparing the results with that of AERONET, we found that the accuracy of the aerosol optical depth (AOD) retrieval was improved with the regression plots concentrating around the $1: 1$ line and two-thirds falling within the expected error (EE) envelope $\mathbf{E E}= \pm 0.05 \pm 0.1 \tau$ (from $53.6 \%$ with $\mathbf{L} \_$FM to $68.7 \%$ with NL_FM at band $0.55 \mu \mathrm{m})$. Surprisingly, more accurate retrieval of the AOD demonstrated significantly improved the Ångstrom exponent (AE) retrieval, which is related to particle size parameters. The regression plots tended to concentrate around the 1:1 line, and many more fell within the $\mathrm{EE}= \pm 0.4$ from $53.6 \%$ with $L_{-}$FM to $80.9 \%$ with $\mathrm{NL}$ _FM. These results demonstrate that including the NL_FM in the MODIS DT algorithm has the potential to significantly improve both AOD and AE retrievals with respect to AERONET in comparison to the L_FM used in the current MODIS operational retrievals.
\end{abstract}

Index Terms-Aerosol optical depth, Ångstrom exponent (AE), bidirectional reflectance distribution functions (BRDF), dark target (DT), Moderate Resolution Imaging Spectroradiometer (MODIS), non-Lambertian forward model (FM) (NL_FM).

\section{INTRODUCTION}

A EROSOL is currently considered one of the largest uncertainties in global radiative forcing [1]. Satellite remote sensing can provide long-term global aerosol distribution, which helps to increase the understanding of aerosol climate effects and decrease its uncertainties [3]. Data from numerous satellite instruments have been employed to obtain aerosol properties over land and ocean [2]. Various algorithms have been developed for aerosol retrieval according to the spectral and angular observation capabilities of the specific instrument. However, remote sensing of aerosol from space is still a challenging task over land. The uncertainty in aerosol retrievals over land remains too large to adequately constrain aerosol radiative forcing on a global basis [16]. For several years, extensive efforts have been undertaken to develop and improve the algorithms, which focus mainly on the reasonable assumption of surface reflectance and aerosol optical properties [2]. However, the accuracy of the forward model (FM) itself introduces uncertainties into aerosol retrieval when an approximated FM is used to simulate top-of-atmosphere (TOA) reflectance.

The Lambertian FM (L_FM), which assumes an isotropic reflectivity assumption from the land surface, has been widely used in the aerosol retrieval algorithm for single-view satellite instruments [5]-[7]. However, it is well known that the anisotropy reflection of the land surface is better described by a bidirectional reflectance distribution function (BRDF) [11]. The approximated L_FM could affect the accuracy of the simulated TOA reflectance matches with the observed ones and then introduce errors into the aerosol optical depth (AOD or $\tau$ ) retrieval. An empirical correction for the surface anisotropy was applied in some algorithms to make a more accurate assumption regarding the surface reflectance [7]. Importantly, many studies of atmospheric correction have successfully improved the reflectance retrieval by accounting for the surface anisotropy [13]-[15]. For aerosol retrieval over land with relatively high surface reflectance and low aerosol contribution, more consideration should be given to the surface anisotropic effect [16].

One commonly used aerosol product has been created from the Moderate Resolution Imaging Spectroradiometer (MODIS) sensors aboard Terra since 2000 and Aqua since 2002. A broad swath $(2330 \mathrm{~km})$ enables MODIS to provide global coverage 
with near daily frequency. The MODIS aerosol product (MOD04) consists of three separate algorithms: dark ocean [17], dark target (DT) over vegetated/dark-soiled land [6], [7], and deep blue over bright desert/arid areas [5]. All three algorithms have been implemented using the current versions of the software in Collection 5.1 (C051). The new version of Collection 6 (C6), which is not altered much from C051, has already finished testing and been published [18]. Here, we only focus on the DT land algorithm, which uses the reflectance in the short-wave infrared (SWIR) $(2120 \mathrm{~nm})$ band, where aerosols are considered negligible, to infer the surface reflectance at two visible (VIS) bands (470 and $650 \mathrm{~nm}$ ) that are then used to retrieve the aerosol loading [6], [7]. Global assessments have indicated that the expected error (EE) of the MODISretrieved AOD by the DT algorithm is $\pm(0.05+0.15 \tau)$ over land compared to that of AERONET [3]. Although validated globally, regional and systematic errors were still found in the MODIS-retrieved AOD [3]. In addition, a number of secondary products, such as the Ångstrom exponent (AE), fine-model fraction (FMF), and fine AOD, showed little physical validity and did not provide reliable particle size information [3]. These products are no longer reported in the C6 version of the MODIS product [18].

Although the systematic errors of the MODIS-retrieved AOD were partly attributed to poor surface and aerosol model assumptions [3], the approximate L_FM with the assumption of isotropic reflectivity for land surface will be an additional source of error, as discussed earlier. In this letter, we present an improved aerosol retrieval algorithm using the non-Lambertian FM (NL_FM) instead of the L_FM in the MODIS DT algorithm to reduce the uncertainties introduced by the Lambertian assumption for the land surface.

\section{DATA AND METHOD}

\section{A. $F M$}

Overlying the Lambertian surface, the TOA reflectance function of a cloud-free and vertically homogeneous earth-atmosphere system can be written as [4], [6]

$$
\rho^{*}\left(\mu_{s}, \mu_{v}, \phi\right)=\rho_{a}\left(\mu_{s}, \mu_{v}, \phi\right)+\frac{T\left(\mu_{s}\right) \rho T\left(\mu_{v}\right)}{1-\rho S} .
$$

Here, the subscript $s$ refers to the solar incidence angle, and the subscript $v$ refers to the satellite view angle. $\mu=\cos (\theta)$, $\theta$ denotes the solar incident angle or the satellite view angle, and $\phi$ is the relative azimuth angle. $\rho^{*}\left(\mu_{s}, \mu_{v}, \phi\right)$ is the TOA reflectance. The first term $\rho_{a}\left(\mu_{s}, \mu_{v}, \phi\right)$ refers the aerosol intrinsic reflectance. The second term denotes the contribution from the surface after multiple scattering within the atmosphere, where $T\left(\mu_{s}\right)$ and $T\left(\mu_{v}\right)$ are the total transmissions for direct and diffuse $\left(T(\mu)=e^{-\tau / \mu}+t_{d}\right)$, respectively, for the downward and upward paths, where $\tau$ is the AOD, $\rho$ is the surface directional reflectance, and $S$ is the spherical albedo of atmosphere. This equation is widely used in aerosol retrieval algorithms for single-view satellite instruments.

When accounting for the surface BRDF, an NL_FM presented in [19] and improved in [20] was employed in this letter for aerosol retrievals

$$
\rho^{*}=\rho_{a}+\frac{\vec{T}\left(\mu_{s}\right) \vec{R} \vec{T}\left(\mu_{v}\right)-\vec{T}\left(\mu_{s}\right)|\vec{R}| \vec{T}\left(\mu_{v}\right)}{1-\rho_{B H R} S} .
$$

Here, $T\left(\mu_{s}\right)=\left[e^{-\tau / \mu_{s}} \mathrm{t}_{d}\left(\mu_{s}\right)\right]$ and $\vec{T}\left(\mu_{v}\right)=\left[e^{-\tau / \mu_{v}} \mathrm{t}_{d}\left(\mu_{v}\right)\right]$ are transmission matrices. $\vec{R}=\left[\begin{array}{cc}\rho & \rho_{D H R} \\ \rho_{H D R} & \rho_{B H R}\end{array}\right]$ denotes the reflectance matrix, where $\rho_{D H R}$ is the directional-hemispherical reflectance (DHR), $\rho_{H D R}$ is the hemispherical-directional reflectance (HDR), and $\rho_{B H R}$ is the bihemispherical reflectance (BHR) equal to the surface albedo. $|\vec{R}|=\rho \cdot \rho_{B H R}-\rho_{H D R}$. $\rho_{D H R}$ is the determinant of the reflectance matrix $\vec{R}$. Using this procedure, the surface directional reflectance $\rho$ in (2) at two VIS bands was derived from the SWIR band using the same method as the MODIS DT algorithm [7]. The BRDF/albedo product MCD43A1 data provide three kernels at $500 \mathrm{~m}$ for the Ross-Thick Li-Sparse model. The data of three kernels are then aggregated to $10-\mathrm{km}$ data. The same polynomial method as that in [10] is used to calculate the integral reflectance of $\rho_{D H R}$, $\rho_{H D R}$, and $\rho_{B H R}$ in (2).

Compared with a full vector atmospheric radiation transfer mode [21], this approximated NL_FM has a high accuracy with relative differences in simulated TOA reflectance less than $0.7 \%$, on average, for different types of surfaces [20].

\section{B. Data}

Because this letter presents improved aerosol retrieval exercises on the basis of the MODIS DT algorithm, the inputs require MODIS Level 1B (L1B) 0.25-, 0.5-, and 1-km reflectances and a 1-km geolocation product [7], [18]. In addition, the ancillary data such as precipitable water from the National Centers for Environmental Prediction reanalysis, daily ozone, and analysis data from the Solar Backscatter Ultraviolet Instrument (SBUV/2) and NOAA's TIROS Operational Vertical Sounder (TOVS) are needed for gas absorption correction [7], [18]. The surface anisotropic (or BRDF) properties were derived from the $0.5-\mathrm{km}$ MODIS BRDF/albedo data product (MCD43A1). The AERONET Version 2.0 Level 2 qualityassured (cloud screened and calibrated) direct-sun measurements of spectral AOD [12] were collected for validation in the study area.

\section{Aerosol Retrieval Method}

Preprocessing, such as the masking of cloud, inland water, and snow/ice, gas absorption correction, and the selection of dark pixels, remains identical with that performed in the MODIS DT algorithm. For additional details, please refer to [7] and [18]. The small modifications include applying a nodata mask when the surface MCD43A1 data are not available.

We used two methods (L_FM and NL_FM) for aerosol retrievals. The first method, L_FM, used the MODIS DT C6 stand-alone code, which was run simultaneously to compare the results with the algorithm using the NL_FM. For the NL_FM method, we modified the retrieval algorithm to calculate TOA reflectance [using (2)] from the same aerosol particle property lookup table used by the MODIS DT algorithm.

Both methods produce the same outputs, such as spectral AOD at 470, 550, and $650 \mathrm{~nm}, \mathrm{FMF}$ at $550 \mathrm{~nm}$, and AE, which is defined using the AOD values, at 470 and $650 \mathrm{~nm}$ [7].

\section{RESULTS}

Aerosol retrievals were applied to MODIS measurements from the whole year of 2008 over Eastern China (Longitude: 

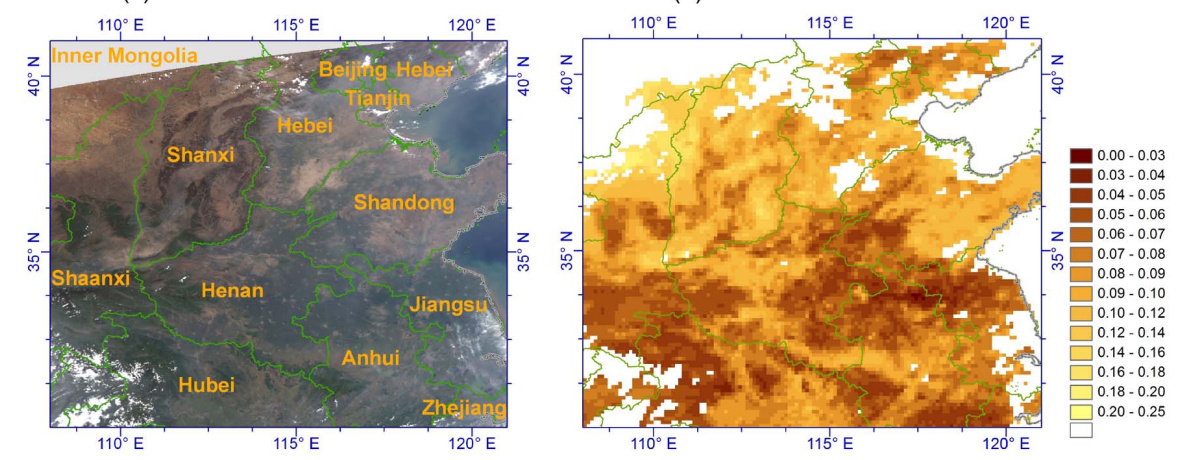

(c) AOD550nm: L FM

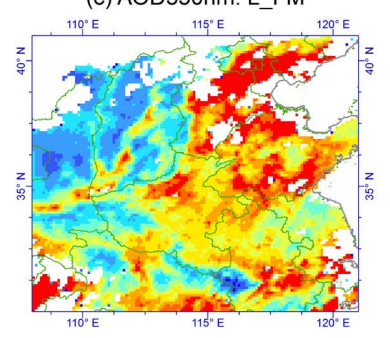

(d) $A$
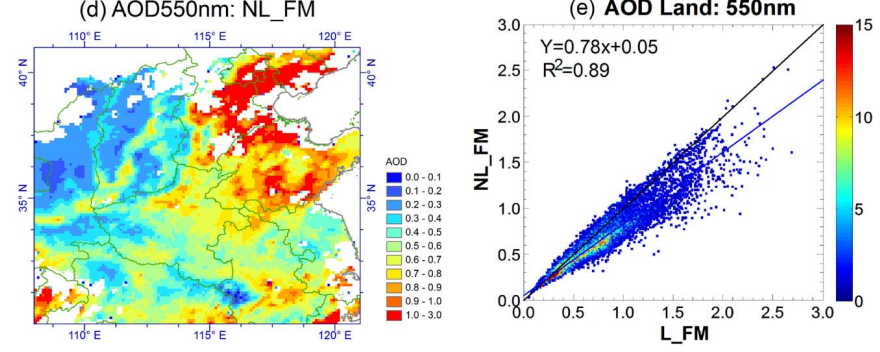

Fig. 1. Granule retrieved over Eastern China from MODIS-Aqua obtained on April 28, 2008 at 05:35 UTC. (a) True color image (RGB). (b) Surface albedo at $650 \mathrm{~nm}$ of the granule. (c) Retrieved AOD at $550 \mathrm{~nm}$ using the C6 DT algorithm based on the L_FM. (d) Retrieved AOD at $550 \mathrm{~nm}$ using the improved algorithm based on the NL_FM. (e) Regression plots of the AOD at $550 \mathrm{~nm}$ comparing between two-way retrievals (c) and (d). Fig. 1(e) includes the one-to-one as well as a linear least squares best fit line, with a slope clearly less than one.

$100^{\circ} \mathrm{E}-125^{\circ} \mathrm{E}$, Latitude: $\left.20^{\circ} \mathrm{N}-50^{\circ} \mathrm{N}\right)$. Because the global yearly trends of AOD retrieval over land from MODIS/Terra tend to decrease while Aqua remains constant [3], only MODIS/Aqua was employed for this experiment.

\section{A. Example of One Granule}

The aerosol retrievals for one granule are given as an example in Fig. 1. As shown in Fig. 1(e), most of the retrieved AODs reduced by the NL_FM algorithm were smaller than those retrieved by the MODIS C6 DT algorithm, which uses the L_FM, although in a few cases, the AODs retrieved with the N_FM were larger. The distributions of the AOD difference $(\triangle \mathrm{AOD}=$ NL_FM-L_FM) between both retrievals are presented in Fig. 2 as a function of aerosol loading and location. Fig. 2(a) was derived from Fig. 1(e), where the average difference and standard deviations of errors were calculated in each bin (totally nine bins) with each bin consisting of 50 measurements (last bin with 53 measurements) using the NL_FM AOD retrieval. In addition, Fig. 2(b) was derived from the absolute difference of Fig. 1(c) and (d). From Figs. 1(a) and (b) and Fig. 2, we found that the change in the retrieved AOD using the NL_FM was significant for relatively brighter surfaces with medium to high loading $(0.5<\tau<2.0)$, while there was less of an effect for darker surfaces at all aerosol loadings or for brighter surfaces with very low (e.g., north Shaanxi, Shanxi, and Inner Mongolia province) or extremely high loadings (e.g., Beijing, Tianjin, Hebei, and Shandong province). This is because the atmospheric path radiance becomes much higher when the aerosol loading is extremely high, and the extinction of the atmosphere makes the surface contribution to the TOA radiance very small so that the effect of surface anisotropy on the aerosol retrieval becomes negligible [19]. These results show that the quality of the MODIS DT AOD retrieval depends on the brightness of the underlying surface as well as the total aerosol loading.
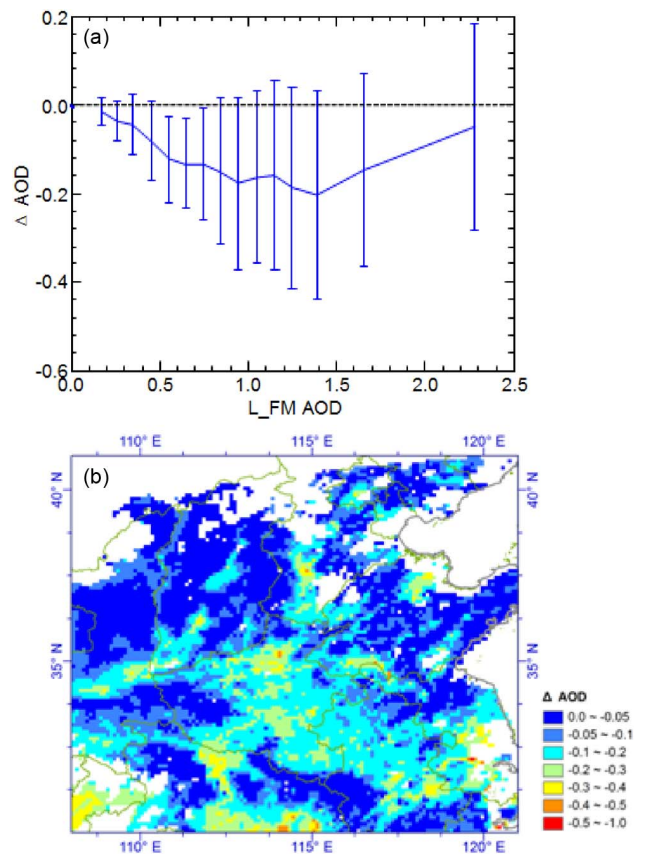

Fig. 2. Distributions of $\mathrm{AOD}$ difference $\left(\triangle \mathrm{AOD}=\mathrm{NL} \_\mathrm{FM}-\mathrm{L} \_\mathrm{FM}\right)$ between both retrievals as function of (a) aerosol loading (binned AOD of L_FM) and (b) location.

For example, in north Henan, south Anhui, and Hubei province (see Fig. 1), the retrieved AOD was high (or overestimated) and inconsistent with the surroundings; additionally, there were no significant high aerosol events in these areas. This may be attributed to their bare soil surfaces, with higher reflectances, and moderately high aerosol loading, which is consistent with the sensitivity study in [4] and [8]. Using the new algorithm based on the NL_FM, this overestimation appears to be largely corrected. 

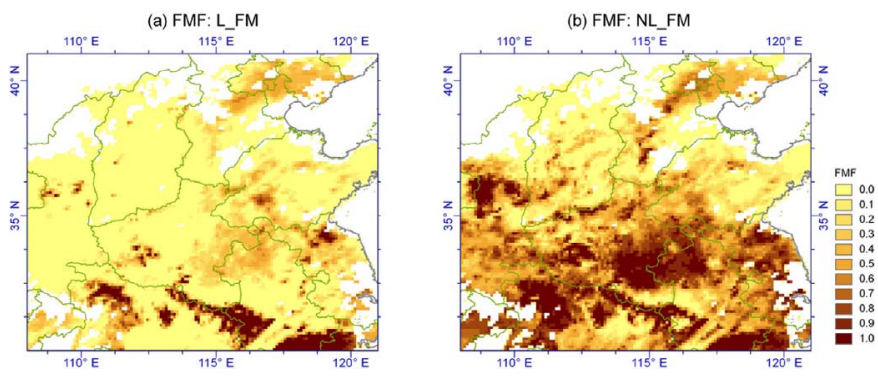

Fig. 3. Retrieved FMF at $550 \mathrm{~nm}$. (a) Using the C6 DT algorithm based on the L_FM. (b) With an improved algorithm based on the NL_FM.
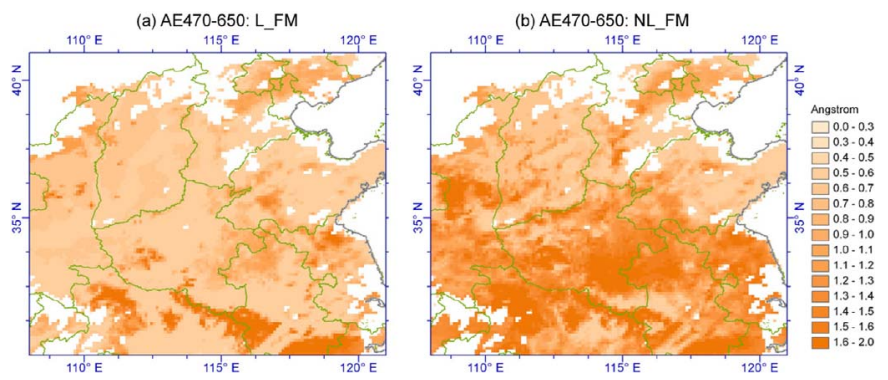

Fig. 4. Retrieved AE defined at 470 and $650 \mathrm{~nm}$. (a) Using the C6 DT algorithm based on the L_FM. (b) Using the improved algorithm based on the NL_FM.

The retrieved FMF at $550 \mathrm{~nm}$ and $\mathrm{AE}$ calculated from the spectral AODs at 470 and $650 \mathrm{~nm}$ are presented in Figs. 3 and 4, respectively. As shown in Fig. 3(a), the FMF using the L_FM showed generally binary results ( 0 or 1$)$, which is also discussed in [3], whereas it has been largely modified using the new algorithm with more pixels falling within $[0,1]$ [see Fig. 3(b)].The binary FMF also resulted in a derived AE close to either 1.8 or 0.5 [3] [see Fig. 4(a)] while the new algorithm produces a much wider range of $\mathrm{AE}$ [see Fig. 4(b)]. In the next section, the AERONET data were employed to quantitatively assess these modifications for the AOD and AE retrievals.

\section{B. Validation of the Retrieved AOD}

The spatiotemporal technique proposed in [9] was used to validate the retrieved AOD from both retrievals (L_FM and NL_FM) against the AERONET observations [3]. The sampling 5 by 5 pixels were used for satellite data, and the temporal measurements from the AERONET location were sampled at each satellite overpass time in 1-h sampling segments (i.e., $30 \mathrm{~min}$ before and $30 \mathrm{~min}$ after the overpass). The regression plots are presented in Fig. 5, and only 453 collocations for year 2008 were matched. These results indicate that the new algorithm based on the NL_FM largely improved the MODIS AOD retrieval in comparison with AERONET. Comparing Fig. 5(a) and (b), the scatterplot with the NL_FM has more points concentrated around the $1: 1$ line, and $68.7 \%$ of the collocated AODs fall within the EE envelope $\mathrm{EE}= \pm 0.05 \pm 0.1 \tau$ (as used in [3]) compared with the L_FM which only has $53.6 \%$ of the points falling with the EE envelope. In addition, the root-meansquare error decreased from 0.17 to 0.12 .

Furthermore, the L_FM retrieval shows a systematic overestimation, with $40.4 \%$ of the retrievals above the EE envelope and $6.0 \%$ below the EE envelope [see Fig. 5(a)], over the study area, while the NL_FM retrieval appears to correct some of this
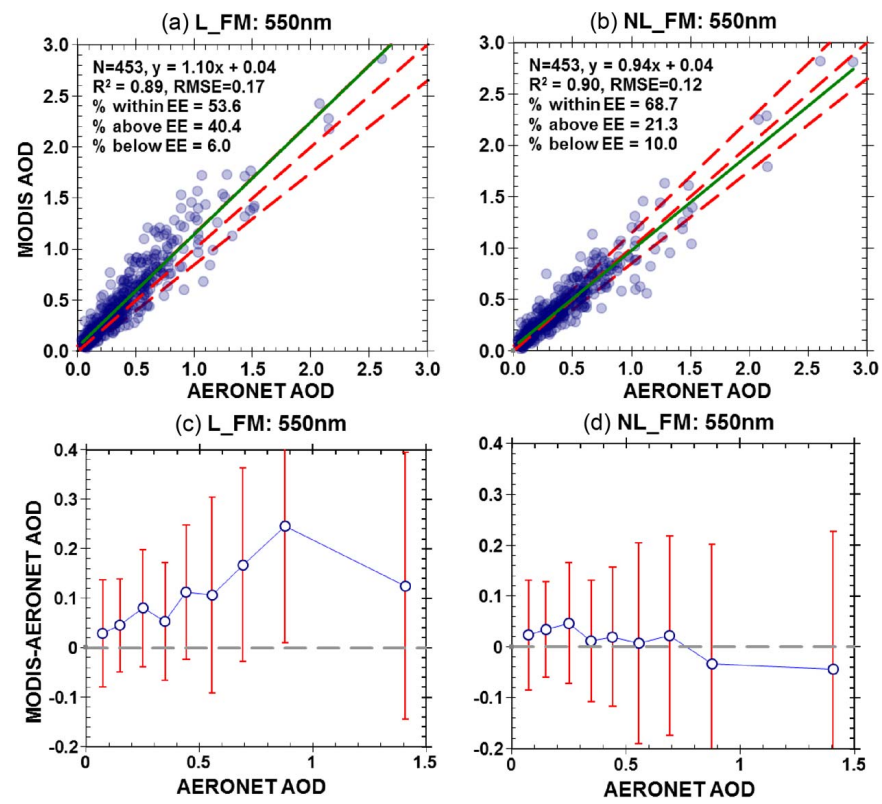

Fig. 5. AOD retrieval from both retrievals (L_FM and NL_FM) compared to the AERONET observation. (a) Scatterplot of the MODIS DT retrieval. (b) Similar to (a) for the new algorithm retrieval based on the NL_FM. (c) Binned average difference of the MODIS-AERONET AOD in (a) as a function of AERONET 550-nm AOD. (d) Similar to (c) but for the new algorithm in (b). EE for AOD is $\pm 0.05 \pm 0.1 \tau$.

overestimation, with only $21.3 \%$ of the retrievals above the EE [see Fig. 5(b)]. The binned MODIS-AERONET difference of Fig. 5(a) and (b), respectively, in Fig. 5(c) and (d) shows that the NL_FM produces AOD retrievals with better agreement with that of AERONET for nearly all ranges of AOD compared with the L_FM. Interestingly, larger average differences of the overestimation in Fig. 5(c) using the MODIS DT algorithm occurred at medium high aerosol loading, in which the shape was similar to the AOD difference of the L_FM-NL_FM in Fig. 2(a).

\section{Validation of $A E$}

In Section III-B, only the scatterplots at $550 \mathrm{~nm}$ are presented, which were calculated using the same method as that in [18]. We compared the spectral AODs retrieved from the MODIS data at 470 and $650 \mathrm{~nm}$ with AERONET and found similar improvement to the retrievals at $550 \mathrm{~nm}$ reported earlier. Although the AE reported in the MODIS aerosol product over land has little physical validity and has been removed from the $\mathrm{C} 6$ product as discussed in [18], we present $\mathrm{AE}$ validation against AERONET in this section based on the observed improvement in the spectral AODs using the NL_FM algorithm. Moreover, the spatial pattern of the retrieved AE shown in Fig. 4 for a single granule also suggests an improvement in the $\mathrm{AE}$ retrieval using the NL_FM algorithm compared with the L_FM.

Comparisons of the AE retrievals calculated using the 470and 650-nm bands for both the L_FM and NL_FM algorithms against AERONET are shown in Fig. 6. Because the aerosol signal at $\tau<0.2$ was most likely too low to retrieve meaningful aerosol size information [3], [7], only the AERONET retrievals with $\tau>0.2$ were used in the comparison. Finally, only 293 collocation data points remained in Fig. 6. As expected [6], most of the retrieved AEs using the L_FM algorithm in the 
(a) L_FM: $470 \sim 650 \mathrm{~nm}$
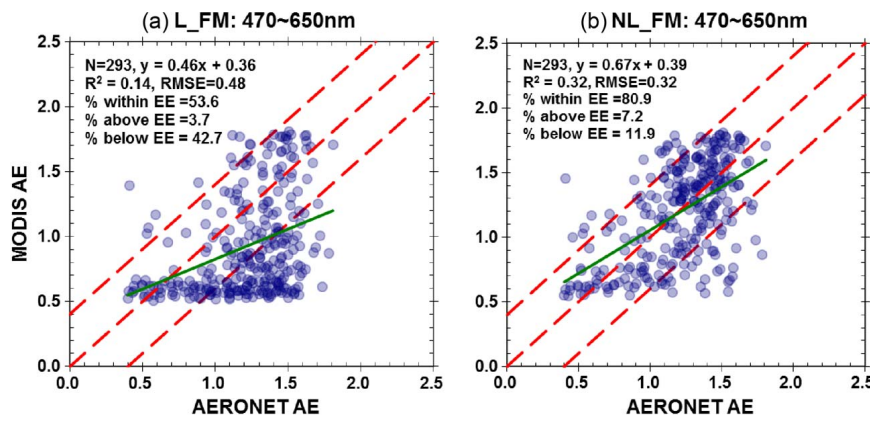

Fig. 6. Scatterplots of retrieved AE against AERONET AOD. (a) With C6 DT algorithm based on L_FM. (b) With improved algorithm based on NL_FM. Only collocations with AERONET $\tau>0.2$ are involved, where EE for AE is \pm 0.4 .

MODIS DT retrievals fall close to $\mathrm{AE}=0.5$, as seen in Fig. 6(a).

However, for the algorithm based on the NL_FM, most of the retrieval tended to concentrate closer to the line $1: 1$ line, as shown in Fig. 6(b). In addition, more of the retrievals fell within the EE envelope of \pm 0.4 [3], with $53.6 \%$ for the L_FM and $80.9 \%$ for the NL_FM.

\section{CONCLUSION}

This letter presents a new aerosol retrieval algorithm using NL_FM in the MODIS DT algorithm to reduce the induced uncertainties introduced by using the L_FM. In general, we concluded that the surface anisotropy introduced uncertainties into aerosol retrieval. Our results indicate that the NL_FM provides a larger correction to the aerosol retrieval for moderate aerosol loadings, where the effects of the surface anisotropy on the TOA reflectances were apt to be largest, as shown in Fig. 5, although the observation and illumination geometry also play a role.

The algorithm based on accurate NL_FM accounted for surface BRDF properties and exhibited the potential to improve the accuracy for satellite aerosol retrieval with $68.7 \%$ versus $53.6 \%$ of the collocated AODs falling within the EE envelope $\mathrm{EE}= \pm 0.05 \pm 0.1 \tau$ with the NL_FM and L_FM, respectively. The L_FM retrieval shows a systematic overestimation, with $40.4 \%$ of the retrievals above the EE envelope, over the study area of Eastern China, while the NL_FM retrieval appears with only $21.3 \%$ of the retrievals above the EE. For the magnitude of surface albedo, the surface anisotropy effect on aerosol retrieval can be scaled, and thus, further validations and site-by-site assessments are needed in the future.

\section{ACKNOWLEDGMENT}

The authors appreciate the MODIS L1B data that are freely distributed by the National Aeronautics and Space Administration (NASA) Level 1 and the Atmosphere Archive and Distribution System (LAADS) and the AERONET data established and maintained by many Principal Investigators and site managers. The authors would like to thank Dr. R. C. Levy for sharing the Moderate Resolution Imaging Spectroradiometer dark-target stand-alone code of C6 and for many useful discussions as well as both the Editor and the reviewers for the constructive detailed comments.

\section{REFERENCES}

[1] T. F. Stocker, D. Qin, G.-K. Plattner, M. Tignor, S. K. Allen, J. Boschung, A. Nauels, Y. Xia, V. Bex, and P. M. Midgley, Eds., Climate Change 2013: The Physical Science Basis. Cambridge, U.K.: Cambridge Univ. Press, 2013, Contribution of Working Group I to the Fifth Assessment Report of the Intergovernmental Panel on Climate Change.

[2] A. A. Kokhanovsky and G. De Leeuw, Satellite Aerosol Remote Sensing Over Land. Berlin, Germany: Springer-Verlag, 2009.

[3] R. C. Levy, L. A. Remer, R. G. Kleidman, S. Mattoo, C. Ichoku, R. Kahn, and T. F. Eck, "Global evaluation of the Collection 5 MODIS dark-target aerosol products over land," Atmos. Chem. Phys., vol. 10, no. 6, pp. 10399-10420, Jun. 2010.

[4] L. Yang, Y. Xue, J. Guang, and C. Li, "Satellite aerosol retrieval using dark target algorithm by coupling BRDF effect over AERONET site," Remote Sens. Atmos., Clouds, Precipitation IV, vol. 8523, SPIE, pp. 85231J-185231J-12, Nov. 2012.

[5] N. C. Hsu, S. C. Tsay, M. D. King, and J. R. Herman, "Aerosol properties over bright-reflecting source regions," IEEE Trans. Geosci. Remote Sens., vol. 42, no. 3, pp. 557-569, Mar. 2004.

[6] Y. J. Kaufman, D. Tanre, L. A. Remer, E. F. Vermote, A. Chu, and B. N. Holben, "Operational remote sensing of tropospheric aerosol over land from EOS Moderate Resolution Imaging Spectroradiometer," J. Geophy. Res., Atmos., vol. 102, no. D14, pp. 17 051-17 067, Jul. 27, 1997.

[7] R. C. Levy, L. A. Remer, S. Mattoo, E. F. Vermote, and Y. J. Kaufman, "Second-generation operational algorithm: Retrieval of aerosol properties over land from inversion of Moderate Resolution Imaging Spectroradiometer spectral reflectance," J. Geophys. Res., Atmos., vol. 112, no. D13, pp. D13211-1-D13211-21, Jul. 2007.

[8] L. Yang, Y. Xue, Y. Li, C. Li, J. Guang, X. He, J. Dong, and T. Hou, "Uncertainty from Lambertian surface assumption in satellite aerosol retrieval," in Proc. Inter. Geosci. Remote Sens. Symp., 2012, pp. 3662-3665.

[9] M. Petrenko, C. Ichoku, and G. Leptoukh, "Multi-sensor aerosol products sampling system (MAPSS)," Atmos. Meas. Tech., vol. 5, no. 5, pp. 913 926, 2012.

[10] C. B. Schaaf, F. Gao, A. H. Strahler, W. Lucht, X. Li, T. Tsang, N. C. Strugnell, X. Zhang, Y. Jin, and J. P. Muller, "First operational BRDF, albedo nadir reflectance products from MODIS," Remote Sens. Environ., vol. 83, no. 1/2, pp. 135-148, Nov. 2002.

[11] J. Guang, Y. Xue, Y. Li, S. Liang, L. Mei, and H. Xu, "Retrieval of aerosol optical depth over bright land surfaces by coupling bidirectional reflectance distribution function model and aerosol retrieval model," Remote Sens. Lett., vol. 3, no. 7, pp. 577-584, 2012.

[12] B. N. Holben, T. F. Eck, I. Slutsker, D. Tanre, J. P. Buis, A. Setzer, E. Vermote, J. A. Reagan, Y. J. Kaufman, T. Nakajima, F. Lavenu, I. Jankowiak, and A. Smirnov, "AERONET-A federated instrument network and data archive for aerosol characterization," Remote Sens. Environ., vol. 66, no. 1, pp. 1-16, Oct. 1998.

[13] B. Franch, E. F. Vermote, J. A. Sobrino, and E. Fédèle, "Analysis of directional effects on atmospheric correction," Remote Sens. Environ., vol. 128, pp. 276-288, Jan. 2013.

[14] Y. Wang, A. I. Lyapustin, J. L. Privette, R. B. Cook, S. K. SanthanaVannan, E. F. Vermote, and C. L. Schaaf, "Assessment of biases in MODIS surface reflectance due to Lambertian approximation," Remote Sens. Environ., vol. 114, no. 11, pp. 2791-2801, 2010.

[15] F.-M. Bréon and E. Vermote, "Correction of MODIS surface reflectance time series for BRDF effects," Remote Sens. Environ., vol. 125, pp. 1-9, Oct. 2012.

[16] Z. Li, X. Zhao, R. Kahn, M. Mishchenko, L. Remer, K. H. Lee, M. Wang, I. Laszlo, T. Nakajima, and H. Maring, "Uncertainties in satellite remote sensing of aerosols and impact on monitoring its long-term trend: A review and perspective," Ann. Geophys., vol. 27, no. 7, pp. 2755-2770, 2009.

[17] L. A. Remer, Y. J. Kaufman, D. Tanré, S. Mattoo, D. A. Chu, J. V. Martins, R.-R. Li, C. Ichoku, R. C. Levy, R. G. Kleidman, T. F. Eck, E. Vermote, and B. N. Holben, "The MODIS aerosol algorithm, products, and validation," J. Atmos. Sci., vol. 62, no. 4, pp. 947-973, Apr. 2005.

[18] R. C. Levy, S. Mattoo, L. A. Munchak, L. A. Remer, A. M. Sayer, and N. C. Hsu, "The Collection 6 MODIS aerosol products over land and ocean," Atmos. Meas. Tech., vol. 6, no. 1, pp. 2989-3034, Jan. 2013.

[19] X. Li, J. Wang, W. Ni, A. H. Strahler, and C. Woodcock, "Simulation of path scattering and multiple bounces of photons between two media (in Chinese)," Sci. China (Series E), vol. 26, pp. 457-466, 1996.

[20] W. Qin, J. R. Herman, and Z. Ahmad, "A fast, accurate algorithm to account for non-Lambertian surface effects on TOA radiance," J. Geophys. Res., Atmos., vol. 106, no. D19, pp. 22671-22684, Oct. 2001.

[21] Z. Ahmad and R. S. Fraser, "An iterative radiative transfer code for ocean-atmosphere systems," J. Atmos. Sci., vol. 39, no. 3, pp. 656-665, Mar. 1982. 